\title{
Editorial
}

\section{Interdisciplinary Approaches and Methods for Sustainable Transformation and Innovation}

\section{Sangkyun Kim}

System \& Management Engineering, Kangwon National University, 1 Kangwondaehakgil, Chuncheonsi, Kangwondo 200-701, Korea; E-Mail: saviour@kangwon.ac.kr; Tel.: +82-33-250-6287

Academic Editor: Marc A. Rosen

Received: 24 March 2015 / Accepted: 1 April 2015 / Published: 3 April 2015

\begin{abstract}
To increase the likelihood of success and sustainability, organizations must fundamentally reposition themselves and try to change current processes or create new products and services. One of the most effective approaches to find a solution for transformation and innovation is to learn from other domains where a solution for similar problems is already available. This paper briefly introduces the definition of and approaches to convergence of academic disciplines and industries, and overviews several representative convergence cases focusing on gamification for sustainable education, environments, and business managements.
\end{abstract}

Keywords: business transformation; innovation; interdisciplinary; gamification

\section{Introduction}

While forecasting the future and changing the current model of your processes or services are always risky. In the increasingly competitive and ever-changing global environments, staying without any changes is even more risky. With the virtue of continuous innovation, organizations can make more efficient service processes and sustain their competitiveness.

Being transformative or innovative does not always mean inventing or creating something new out of nothing. Sometimes, we can find a way of changing the existing processes or products to get a more competitive edge by a making shift in thinking to find solutions from the available ones, or by combining two or more industries, academic disciplines, professions, or technologies. For example, Nike made Nike+ based on the lessons learned from traditional popular games. Some game elements, such as a progressive bar, point system, and badges, were applied to Nike+. Thus, Nike found a new way to 
innovate its products not from the shoes industry, but from the game industry. In doing so, a new value with converging two industries was created.

This paper introduces the definition and approaches of convergence of academic disciplines and industries; furthermore, several remarkable cases of convergence focusing on game disciplines are summarized.

\section{Convergence of Academic Disciplines and Industries}

Yoffie defined the convergence as "the unification of function; the coming together of previously distinct products that employ digital technologies" [1]. Rold proposed that the convergence mainly occurs between telecommunications, information technology, content, and services [2]. Convergence is expected to create a new service or product for organizations that will increase their value in increasingly competitive and connected environments.

Business convergence between different industries creates a new business model. It merges the competitive value of two or more business units to overcome the existing limitations of each of the business units at stake. It is a strategy where the enterprises that face the limitation of on-going growing with their own technology or business model merge or ally their competitiveness to improve their own technology or business model, or to make a creative business model [3].

Considering the impact of industry convergence on industry dynamics and business strategy, Stieglitz [4] classified it into four types (see Table 1). First, industry convergence was categorized into technological convergence and product-based convergence. The former, technological convergence, was further subdivided into two generic types: technological substitution and technology integration. Technological substitution means that new technologies from other industries replace existing technologies of established industries. Thus, it is the industry convergence by technology substitution. Technology integration means that various technologies previously used in different industries are blended and integrated. Technology integration commonly boosts new markets. Product-based convergence has two generic types, namely, product substitution and product complementarity. Product substitution means that an existing product integrates some features of other products in another industry. Companies improve or expand their established products adopting new features from other industries. Product complementarity means that formerly unrelated products evolve into mutual complements. Customers mostly use these products simultaneously or together for better usability.

Table 1. Types of Industry Convergence by Stieglitz [4].

\begin{tabular}{ccc}
\hline & Substitute & Complement \\
\hline Technological Convergence & Technological Substitution & Technology Integration \\
Product-based Convergence & Product Substitution & Product Complementarity \\
\hline
\end{tabular}

\section{Recent Cases of Convergence}

This section introduces some noteworthy cases focusing on gamification which transform or innovate existing processes, products, or services by using game disciplines for the sustainable growth. Gamification means a use of game mechanisms and dynamics on non-game services and products, such as the government, manufacturing, education, health care, and the military. The formal definition 
of this concept was made at CHI2011. During the past four years, several cases of gamification have been developed in various areas.

\subsection{Application of Game Disciplines for Sustainable Education}

Papastergiou shows that, compared to the non-gaming approach, the gamified class is more effective in improving students' knowledge and enhancing their motivation [5]. By satisfying the students' needs for fun and pleasure, the gamified class would motivate the students to be immersed in classroom.

Class123 is a gamified application for school teachers which effectively manages students' behavior in classroom and transparently shares students' daily lives with their parents [6]. It consists of a PC web service and a mobile web/app service for teachers, parents, and students. A teacher can collect students' behavioral data and deliver feedback to students quickly and easily from both computers and mobile devices. As shown in Figure 1, a classroom PC or TV becomes a live leader board presenting students' gamified avatars and feedback animations. Teacher's mobile device becomes a remote controller for this leader board. With Class123, teachers can share behavior reports and announcements with parents and students, as well as communicate with parents to cooperatively promote students development.

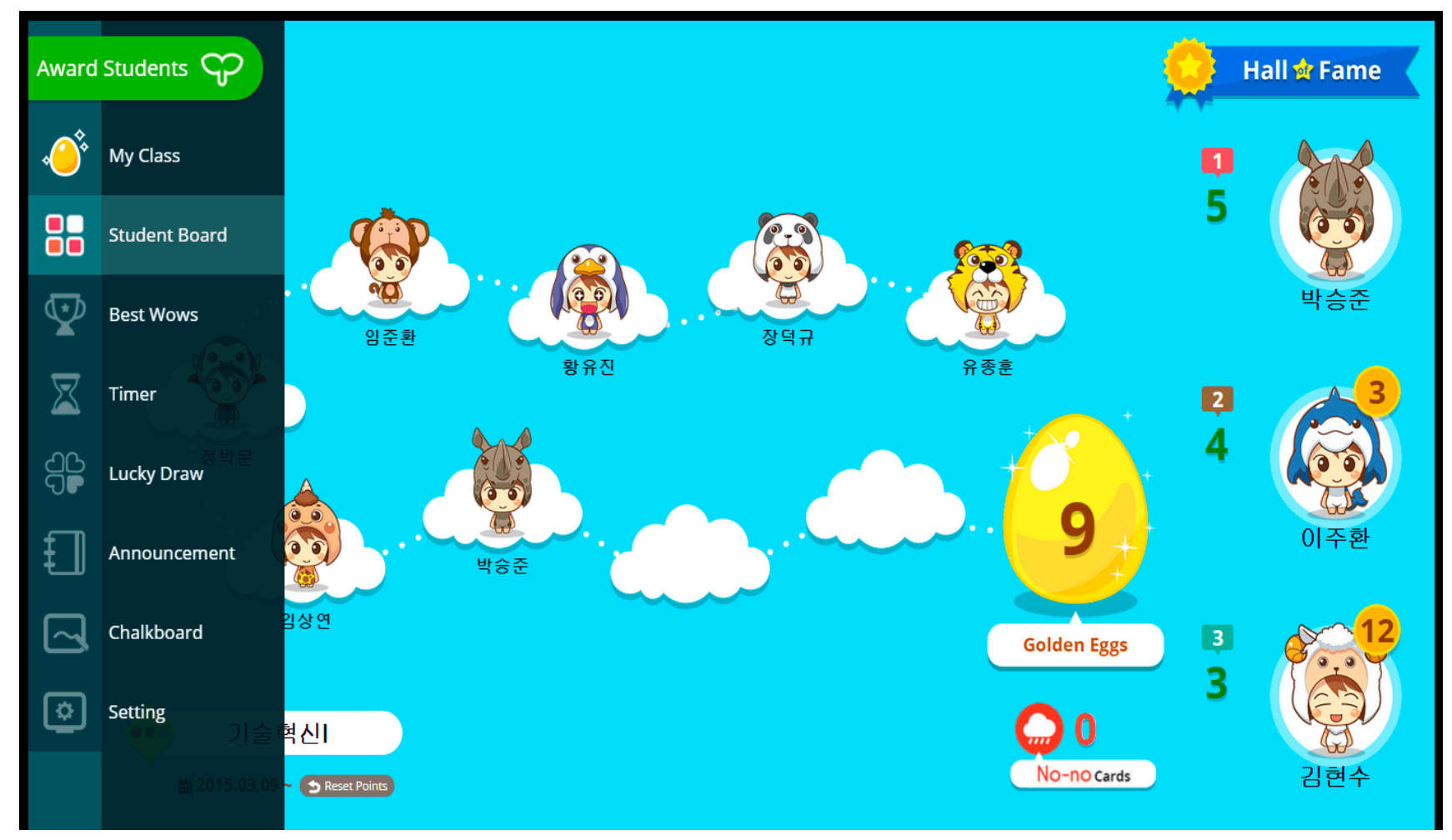

Figure 1. Class 123.

Kim demonstrated that the feedback using Class 123 is effective in motivating students and increases the students' perception of correctness and fairness of teacher's feedback [6]. 


\subsection{Application of Game Disciplines for Sustainable Environments}

The Leaf is an all-electric vehicle manufactured by Nissan. In most aspects, Nissan Leaf is very similar to a conventional gas vehicle. The major difference with a conventional gas vehicle is a limited range of driving due to the electric battery capacity. In Nissan Leaf, the Eco Mode software tracks several variables related with energy consumption [7]. The Eco Mode software monitors accelerator pedal operation, brake pedal operation, driving conditions, traffic conditions, heater and air conditioner usage, the time when the vehicle is not moving while it is ready to go. As shown in Figure 2, a display behind the steering wheel provides a feedback of energy efficiency. The level of energy efficiency is shown by providing tree symbols. It also provides online profiles which describe a ranking compared to others.

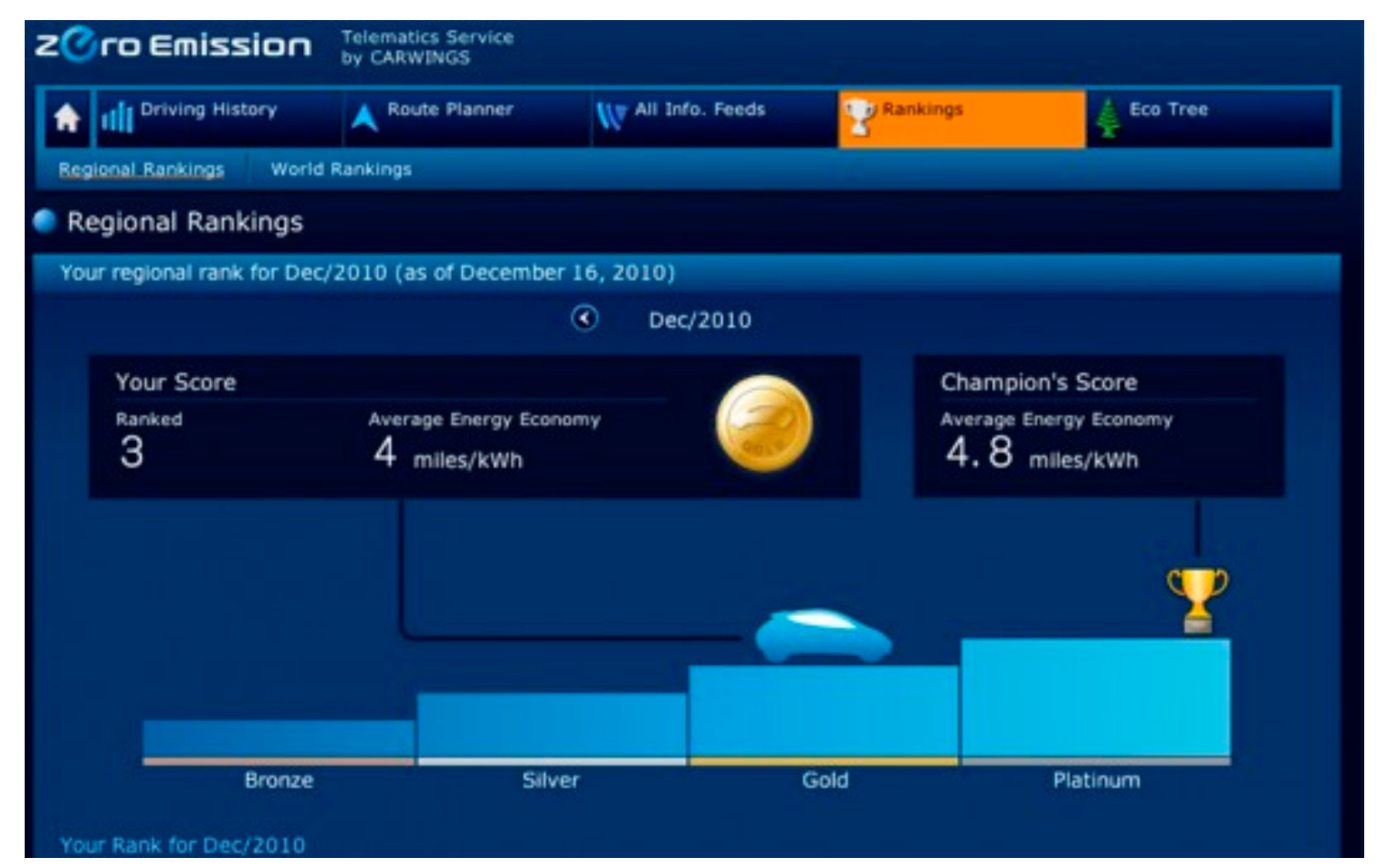

Figure 2. Nissan Leaf.

SUMO (Sustainability Momentum) is a cloud app which aims to improve sustainability in an organization. SUMO's purpose is to save both money and the environment. As shown in Figure 3, this app provides a game-like user interface and is available on mobile devices. Using SUMO, employees can compare their own sustainability level with that of others. It shows the organizational performance of sustainability in real time and compares the current status of an organization with that of other organizations [8]. An average saving rate of the organizations that have implemented SUMO is $9 \%$. The ultimate goal of SUMO is to reduce the organizational carbon footprint. In this sense, SUMO has a similar goal with Nissan Leaf [9]. 


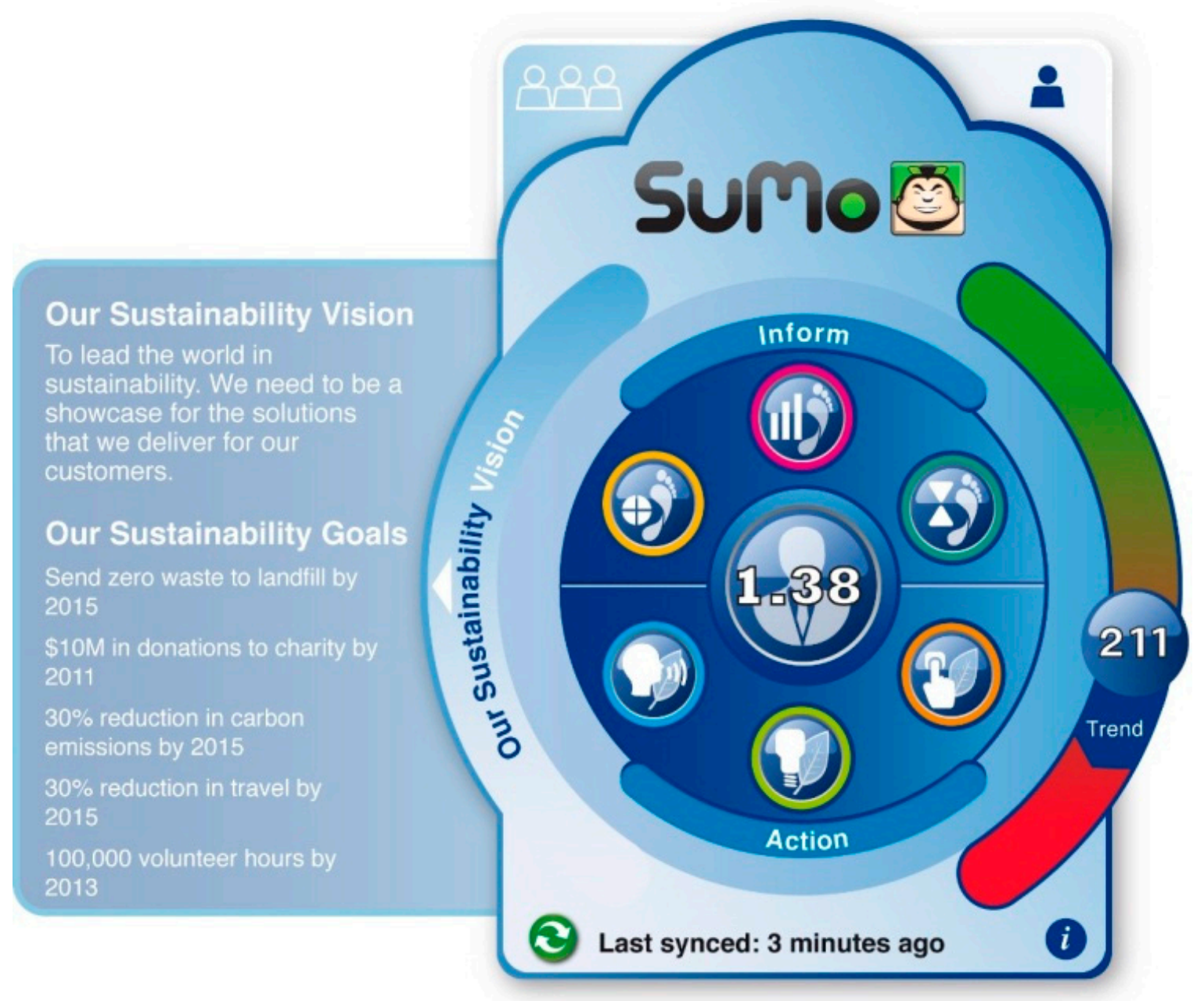

Figure 3. SUMO.

\subsection{Application of Game Disciplines for Sustainable Business Management}

As shown in Figure 4, Taskville looks like a famous city-building game SimCity. In Taskville, the completion of tasks leads to the growth of building and cities in the game field. Each city means a group of individuals in a big organization. The play status of Taskville is shown on large display; players complete their real-world tasks and submit a completion of task and a building in their own city is growing [10]. Using Taskville, the players who are members of a big organization become more aware of the work of other employees in their organization. However, a definition of the task is a very important factor. Two players who spend the same amount of time to accomplish their tasks could have different numbers of buildings because the task in Taskville depends on personal definition. 


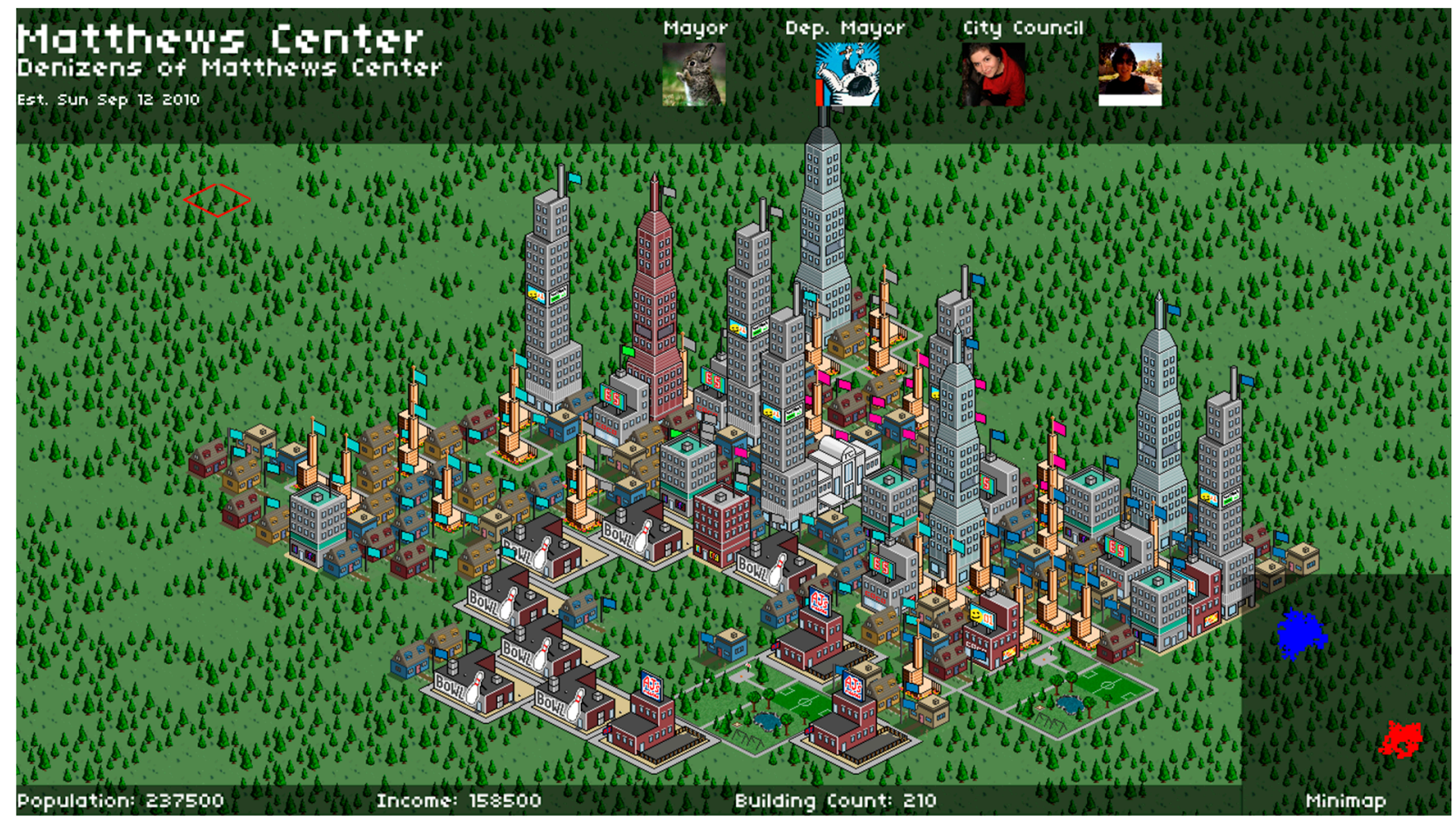

Figure 4. Taskville.

\section{Conclusions}

In order to survive in the present-day changing environments, organizations must adapt themselves. In biology, the relevant metric is "fitness," measured as the relative ability of an organism to breed successfully in a given environment. "Adapting" means continually improving fitness, in particular, as the environment changes [11]. To effectively and rapidly improve fitness in changing environments, we should learn how we can adapt ourselves from other academic disciplines or industries. The more adaptive an organization or a firm is, the greater its ability to improve its fitness to respond to the changes in its market, industry, or technology.

This paper briefly introduced the definition of and approaches to convergence of academic disciplines and industries and overviewed several gamification cases for sustainable education, environments, and business managements.

\section{Acknowledgments}

This research was supported by Basic Science Research Program through the National Research Foundation of Korea (NRF) funded by the Ministry of Education (NRF-2013R1A1A2A10058460).

\section{Conflicts of Interest}

The authors declare no conflict of interest.

\section{References}

1. Yoffie, D.B. Competing in the Age of Digital Convergence; Harvard Business School Press: Boston, MA, USA, 1997. 
2. Rold, C.D. Service Market: Technical Convergence; Gartner Inc.: Stamford, CT, USA, 2002.

3. Kim, S; Leem, C.S. Enterprise security architecture in business convergence environments. Ind. Manag. Data Syst. 2005, 105, 919-936.

4. Stieglitz, N. Strategie und Wettbewerb in konvergierenden Märkten; Deutscher Universitäts-Verlag: Wiesbaden, Germany, 2004.

5. Papastergiou, M. Digital game-based learning in high school computer science education: Impact on educational effectiveness and student motivation. Comput. Educ. 2009, 52, 1-12.

6. Kim, S. The educatees' response on feedback using app. J. Korea Game Soc. 2015, in press.

7. Lee, D. What is gamification and how gamification will change our life? Digit. Des. Res. 2011, 6, 450-457.

8. CloudApps SuMo Packs a Sustainable Punch. Available online: http://goo.gl/ihMcph (accessed on 18 March 2015).

9. Kim, S. Recent advances in gamification application. Adv. Inf. Sci. Serv. Sci. 2013, 5, 93-99.

10. Nikkila, S.; Linn, S.; Sundaram, H.; Kelliher, A. Playing in Taskville: Designing a Social Game for the Workplace. In Proceeding of the Conference on Human Factors in Computing Systems, Vancouver, BC, Canada, 7-12 May 2011.

11. Meyer, C.; Davis, S. It's Alive; Crown Business: New York, NY, USA, 2008.

(C) 2015 by the authors; licensee MDPI, Basel, Switzerland. This article is an open access article distributed under the terms and conditions of the Creative Commons Attribution license (http://creativecommons.org/licenses/by/4.0/). 